\title{
Racial and Ethnic Disparities in Cardiovascular Disease: An Assessment of Obstetrician-Gynecologists' Knowledge, Attitudes, and Practice Patterns
}

\author{
Katherine M. Jones • Michele M. Carter • Jay Schulkin
}

Received: 25 June 2014 /Revised: 29 January 2015 / Accepted: 2 February 2015 / Published online: 5 March 2015

(C) W. Montague Cobb-NMA Health Institute 2015

\begin{abstract}
Background African American and Hispanic women are disproportionately affected by cardiovascular disease (CVD) and its many risk factors. Obstetrician-gynecologists (OB/GYNs) play an integral role in well-woman care and have a unique opportunity to provide CVD counseling and screening to these at-risk and underserved groups.

Objective To assess whether $\mathrm{OB} / \mathrm{GYN}$ race/ethnicity and $\mathrm{OB} /$ GYN practices with increasing minority patient populations predicted differences in $\mathrm{OB} / \mathrm{GYNs}$ ' knowledge, attitudes, and practice patterns relevant to racial/ethnic disparities in CVD. This study also sought to determine provider and patientrelated barriers to CVD care.

Method A questionnaire on CVD was mailed to 273 members of The American College of Obstetricians and Gynecologists in March-July 2013.

Results African American and Hispanic OB/GYNs and OB/ GYN practices with increasing minority patient populations were more knowledgeable of CVD disparities. These OB/ GYNs reported greater concern for minority women's CVD risk relative to White $\mathrm{OB} / \mathrm{GYN}$. Overall, $\mathrm{OB} / \mathrm{GYNs}$ appear less knowledgeable and concerned with Hispanics' increased CVD risk relative to African Americans'. The most commonly reported provider and patient-related barriers to CVD care
\end{abstract}

K. M. Jones $(\bowtie) \cdot J$. Schulkin

Department of Research, The American College of Obstetricians and Gynecologists, 409 12th Street SW, Washington, DC 20024, USA

e-mail: kjones@acog.org

J. Schulkin

e-mail: jschulkin@acog.org

K. M. Jones $\cdot$ M. M. Carter

Department of Psychology, American University, 4400

Massachusetts Avenue NW, Washington, DC 20016, USA

M. M. Carter

e-mail: mcart@american.edu were time constraints, patient nonadherence to treatment recommendations, and inadequate training.

Conclusion It is likely that minority OB/GYNs and those with practices with increasing minority patient populations have greater exposure to women at risk for CVD. Dissemination of educational information regarding Hispanic women's CVD risk profile may improve OB/GYN knowledge, counseling, and screening. Increased training in CVD and multicultural competency during medical school and residency should help OB/ GYNs overcome what they report as primary barriers to CVD care.

Keywords Racial/ethnic disparities - Cardiovascular disease · African American · Hispanic · Women's health ·

Obstetrician-gynecologists

\section{Introduction}

Cardiovascular disease (CVD) is the leading cause of death and disability among women in the USA [1]. African American and Hispanic women are disproportionately affected by CVD and its many risk factors, including hypertension, obesity, diabetes, physical inactivity, high cholesterol, and metabolic syndrome [2]. Racial discrimination is an added psychological stressor for African American and Hispanic women $[3,4]$ that partly contributes to the disparity in CVD [5]. Perceived racial discrimination results in an amplified psychological and physiological stress response [6]. Repeated exposure to acute episodes of racial discrimination can result in a chronic, physiological, anticipatory state that can remain present even in the absence of racist or discriminatory acts, resulting in increased blood pressure and cardiovascular reactivity [3, 7-9].

Racial and ethnic disparities in CVD are impacted by other factors, including patient, healthcare, and provider variables. 
African American and Hispanic women have a higher burden of sociodemographic risk factors, including income, education, insurance coverage, urbanicity, and limited access to healthy foods and safe areas for exercise [10-12]. Moreover, patients' health beliefs, cultural factors, low health literacy rates, mistrust in physicians and the health care system, and low adherence to medical recommendations perpetuate disparities in CVD [13].

Inequalities in access to care and healthcare quality contribute to poorer health outcomes among minority women [13]. Minority women are less likely than Whites to receive needed medical services and routine treatment for CVD and diabetes [14]. In cardiac care, minority patients are less likely than Whites to receive catheterization, transplants, pharmacological therapy, and bypass surgery even when procedures are judged necessary [15]. In contrast, minorities are more likely than White patients to receive poorer quality care and unfavorable procedures, such as lower extremity amputations for diabetes and critical limb ischemia $[15,16]$. In a recently published paper, Capers and Sharalaya reviewed the current status of racial/ethnic disparities in four areas of CVD care [16]. Their findings indicated that even after adjusting for socioeconomic status, inability to pay, and patient insurance, African Americans and Hispanics were less likely than Whites to receive cardiac resynchronization therapy with defibrillator (CRT-D) implantation in patients with advanced heart failure. African Americans were also less likely than Whites to receive automatic implantable cardioverterdefibrillator (AICD) implantations in patients at risk for sudden cardiac death, coronary reperfusion therapies in patients with acute myocardial infarction, and revascularization in patients with critical limb ischemia [16].

It is important to note that less aggressive risk factor management also contributes to racial and ethnic disparities in CVD among African Americans and Hispanics [17]. Research indicates that although African American and Hispanic women have a higher prevalence of risk factors and poorer CVD outcomes at a population wide level, their lifetime risks of death from CVD are similar to Whites when their risk profiles are comparable [18]. When sociodemograpic and CVD risk factors are well controlled for, racial disparities in cardiovascular outcomes, including mortality, disappear [19]. There is also variation in cardiac risk factors between racial and ethnic subgroups both in the USA and in other geographic areas, such as Latin America and Eastern and Southern Europe [20-29]. Evidence suggests that more aggressive risk factor control may be key to bridging the gap in racial disparities in CVD [17].

Provider-related variables such as lack of cultural competency and racial biases in medical decision-making may also impact CVD disparities [26]. Research suggests that physicians' diagnostic and treatment decisions, as well as their overall attitudes about their patients, are influenced by patient race/ethnicity [14]. Lastly, the underrepresentation of minority physicians in the medical profession has been well documented for decades and may further contribute to racial disparities in CVD because minority providers are more likely to care for minority patients $[27,28,42]$.

Obstetrician-gynecologists $(\mathrm{OB} / \mathrm{GYNs})$ play an integral role in well-woman care and are often the first and most frequent point of medical contact for women [29, 30]. In fact, many women report that their OB/GYN is their only source of routine health care [31]. Low-income, non-White women, who are younger, less educated, and who have small children are more likely to utilize their $\mathrm{OB} / \mathrm{GYN}$ as a primary care provider (PCP) [32]. In a study of low-income women, $38 \%$ of those surveyed considered their $\mathrm{OB} / \mathrm{GYN}$ to be their PCP [30]. The current study does not assert that OB/GYNs should be in charge of managaging their patients' CVD health. However, OB/GYNs have a unique opportunity to provide patients, particularly at-risk and underserved minority women, with CVD counseling and screening. The American College of Obstetricians and Gynecologists (ACOG) guidelines state "the $\mathrm{OB} / \mathrm{GYN}$ can educate, screen, monitor, and treat women to reduce their risk of morbidity and mortality from CVD" [33]. ACOG guidelines recommend that OB/GYNs provide counseling and offer interventions and referrals for hypertension, obesity, diabetes, dyslipidemia, smoking cessation, physical exercise, and diet.

Although research on CVD is extensive, the lack of knowledge regarding heart disease among physicians [34, 35] and their female patients [36, 37] is concerning. Mosca et al. [35] invited 8,550 physicians from a national database of health care professionals to participate in a cross-sectional online survey that included standardized questions about awareness of and barriers to CVD prevention guidelines and physician CVD preventive practice patterns. Of those who were sent an invitation, 500 physicians (300 PCPs, 100 OB/GYNs, and 100 cardiologists) responded, for a total response rate of $17 \%(13,10$, and $15 \%$ among PCPs, OB/GYNs, and cardiologists). Less than one in five physicians knew that more women than men die yearly from CVD. Only half of all physicians counseled their patients on healthy dieting, and less than two thirds recommended physical activity to patients. OB/GYNs were less likely to be aware of national guidelines for cholesterol and blood pressure levels than PCPs.

Ehrenthal et al. [38] conducted a qualitative study of 46 $\mathrm{OB} / \mathrm{GYN}$ residents and practicing physicians in Delaware and Pennsylvania to assess $\mathrm{OB} / \mathrm{GYNs}$ ' perceptions regarding the comprehensive health care of their non-obstetric patients. Similar to previous findings [39], the majority of OB/GYNs reported that they provide only pregnant patients with both reproductive and non-reproductive care. Physicians reported that besides obesity and smoking, care not focused on reproductive issues for non-pregnant patients was beyond their scope of practice. 
A more recently published study by Ehrenthal et al. [40] evaluated the efficacy of the 3-year tristate (Delaware, Ohio, New York) Heart Truth Professional Education Campaign. Healthcare professionals and students in the health professions were invited to attend a 1-h continuing medical education lecture based on the 2007 American Heart Association (AHA) guidelines for CVD prevention in women and to complete a pretest and posttest evaluation. The pretest assessed perceived CVD knowledge and preparedness and actual knowledge of AHA guidelines on CVD. The posttest included identical knowledge questions and additional questions about the participant's perceived utility of the lecture. Physicians were interns, residents, and practicing providers who selfidentified as family practitioners, general internists, OB/ GYNs, cardiologists, "other MD or DO", nurse practitioners (NP), physician assistants (PA), or registered nurses. Students included medical, nursing, pharmacy, and other studies in the health professions. A total of 2,995 participated in the educational campaign ( $43.3 \%$ family practitioners, $21.1 \%$ internists, $13.4 \% \mathrm{OB} / \mathrm{GYNs},<2 \%$ cardiologists, $29.5 \%$ nurses, $12.3 \%$ students, $8.3 \%$ NP/PAs). Sixty-three percent $(1,893)$ of participants completed both the pre- and posttests (13.6\% family practitioners, $6.0 \%$ internists, $1.7 \% \mathrm{OB} / \mathrm{GYNs}, 1.6 \%$ cardiologists, $4.8 \%$ other physicians, $7.4 \%$ NP/PAs, $29.3 \%$ registered nurses, $16.0 \%$ students, $12.8 \%$ other, $6.6 \%$ did not specify their area of training). Among physicians, $\mathrm{OB} / \mathrm{GYNs}$ had the lowest actual knowledge scores at baseline. OB/GYNs $(53.1 \%)$ were least likely to know that African Americans, Hispanics, and Asian Americans are at high risk for diabetes relative to all other physicians. OB/GYNs $(84.8 \%)$ scored second highest in being able to identify that African American women are most likely to die from heart disease relative to all women. The majority of OB/GYNs were knowledgeable about seven of the eight AHA guidelines assessed at pretest; however, OB/GYNs ( $23 \%$ ) were least likely to be knowledgeable regarding AHA guidelines on the correct use of statins in women to prevent CVD. Of all physicians, OB/ GYNs had the highest posttest scores and the second highest change in mean scores between pre- and posttests.

Results from national telephone surveys of women reveal that approximately half of respondents knew that CVD was their leading cause of mortality [36, 37]. African American and Hispanic women were significantly less likely than White females to know that CVD is their leading cause of death (38 and $34 \%$ vs. $62 \%$, respectively) [37]. These minority groups were significantly less knowledgeable than White females about healthy levels of CVD risk factors, such as healthy blood pressure and LDL/HDL cholesterol levels. Of importance, women who had received information about CVD in the last 12 months or who knew that CVD was their leading cause of mortality were significantly more likely to take preventive action by losing weight, decreasing their intake of unhealthy foods, and increasing physical activity.
Unfortunately, the lack of CVD knowledge among minority women does not seem to be improving. A recent study found that Hispanic women $(27 \%)$ were significantly less likely than White women $(88 \%)$ to know that CVD is their leading cause of death [41]. Findings from these studies underscore the meaningful impact that $\mathrm{OB} / \mathrm{GYNs}$ can have by counseling their minority patients regarding their increased CVD risk as well as providing screening and referral services.

The primary aim of this study was to assess whether OB/ GYN practices with increased minority (i.e., African American and Hispanic) patient populations predicted differences in OB/GYNs' knowledge, attitudes, and practice patterns of racial and ethnic disparities in CVD. The second aim of this study was to determine provider and patient-related barriers to CVD care. The third aim of this study was to examine whether African American and Hispanic providers differed in these areas given that minority providers are more likely to care for minority patients [42]. Provider race/ ethnicity has been associated with differences in medical decision-making and end-of-life treatment $[16,43,44]$. The few studies that have assessed OB/GYN CVD knowledge in women have utilized small and/or geographically limited samples $[35,38,39]$. This is the first study to utilize a larger, nationally representative sample of $\mathrm{OB} / \mathrm{GYNs}$ to assess $\mathrm{OB} /$ GYNs' CVD knowledge, attitudes, and practice patterns relevant to racial and ethnic disparities in CVD among women.

\section{Method}

\section{Participants}

Participants were 273 ACOG fellows and junior fellows who are active members of the Collaborative Ambulatory Research Network (CARN). CARN is a nationwide sample of ACOG fellows and junior fellows who volunteer to participate in research studies. CARN members are a representative sample (by age, gender, and geographic location) of the ACOG membership, of which more than $90 \%$ of OB/GYNs in the USA are members.

The purpose, risks, and benefits of the study were outlined in an accompanying cover letter. Return of the completed questionnaire indicated consent to participate in the study. Participation was voluntary, with no compensation offered to participants.

\section{Measures}

A survey regarding OB/GYN knowledge, attitudes, and practices relevant to racial and ethnic disparities in CVD was developed by the Department of Research at ACOG in consultation with practicing $\mathrm{OB} / \mathrm{GYNs}$ familiar with disparities in CVD. The questionnaire was pilot tested on a sample of 
practicing OB/GYNs with appropriate adjustments made before distribution. Institutional review board approval was obtained from American University.

Respondents were not provided with information on cardiovascular health and were instructed not to look up any information in order to gauge OB/GYN knowledge, as opposed to research skills. The survey consisted of 39 questions pertaining to provider/patient demographics and provider knowledge, attitudes, and practices of racial/ethnic disparities in CVD among African American and Hispanic women. Demographic questions included the OB/GYN's year of birth, gender, race/ethnicity, number of years in practice, type of practice, primary medical specialty, practice location, and $\mathrm{racial} / \mathrm{ethnic}$ distribution of patient population.

Knowledge of racial/ethnic disparities in CVD was measured by creating a knowledge score based on a subset of forced-choice survey questions, which assessed OB/GYN awareness of African American and Hispanic women's increased CVD risk. OB/GYNs were asked to rate the prevalence of 12 CVD risk factors among their minority patients relative to White women in their practices. Based on these questions, a risk score was calculated to further describe $\mathrm{OB} /$ GYNs' perceived CVD risk of their patient populations. One vignette was included in the questionnaire in which $\mathrm{OB} /$ GYNs were asked whether their concern for a patient borderline on a number of objective, physical measures of CVD risk factors (e.g., BMI, hypertension, high cholesterol, etc.) would increase if she were African American, Hispanic, or White. This vignette was developed to assess whether patient race/ ethnicity plays an important role in $\mathrm{OB} / \mathrm{GYN}$ medical decision-making with regards to CVD care.

\section{Procedure}

All participants were sent an introductory letter, a questionnaire on CVD, and a postage-paid return envelope. Those who did not respond after the first mailing were sent up to two reminder mailings in April-May 2013. Finally, those who did not respond to the questionnaire were sent a letter containing six of the survey items along with a postage-paid return envelope. The letter responses were used to assess for potential non-response bias.

\section{Data Analysis}

Data were analyzed using a statistical software package, SPSS 20.0 (IBM SPSS Statistics 20.0, IBM Corp. (C), Armonk, NY). Differences between letter and survey responders were compared on all 6 items on the letter mailing. Descriptive statistics were computed for measures used in analysis and reported as mean values \pm standard deviation. Chi-square test was performed for categorical analyses. One-way analysis of variance (ANOVA) was used to compare group means of continuous variables. Linear and logistic regressions were used to determine whether $\mathrm{OB} / \mathrm{GYN}$ practices with increasing minority patient populations predicted differences in $\mathrm{OB} / \mathrm{GYNs}$ ' knowledge, attitudes, and practice patterns as they relate to racial/ethnic disparities in CVD. The mean percentage of minority patient populations was calculated as a continuous variable by combining the percentage of African American and Hispanic patients that $\mathrm{OB} / \mathrm{GYN}$ reported having in their practices. Instead of picking an arbitrary cut-off as to what qualified as high minority patient populations (i.e., creating a dichotomous variable) and thus risk losing valuable data, this study looked at the total percentage of minority patients as a continuous variable in order to have the most accurate, predictive model. The mean percentage of minority patients was used in data analysis as the main predictor variable. Results for main analysis are reported as they relate to OB/GYN practices with increasing minority patient populations analyzed on a continuum. Linear and logistic models were used to calculate predicted probabilities and their corresponding $95 \%$ confidence intervals. Findings were reported as significant at $p<0.05$. All analyses accounted for years in practice and gender, given that recency of training [45] and gender [46, 47] have been found to be associated with differential clinical practice.

\section{Results}

A total of 187 questionnaires were returned, resulting in an overall response rate of $69 \%$. Of the total responders, 158 returned a completed survey and 23 returned a completed letter. Questionnaires from six respondents were judged invalid (provider retired, provider opted out, returned to sender). Thus, these surveys were excluded from analysis. Because the letter responses were only used for comparative analysis to determine differences in survey responders and nonresponders, they are not included in the main results. No significant demographic differences were found between letter and survey responders. Two small, but statistically significant differences were found in survey responses between respondents and non-respondents.

Half of respondents were female $(50 \%)$. The mean age of $\mathrm{OB} / \mathrm{GYNs}$ was 55.8 years ( $\mathrm{SD}=9.4$ years), and they had an average of 22.8 years in practice ( $\mathrm{SD}=9.6$ years). The average age of respondents is representative of ACOG members who belong to CARN (54.0 \pm 10.0 years) and is consistent with recent studies that sampled CARN and non-CARN members $(55.6 \pm 9.3$ years [48]; $54.0 \pm 9.4$ years [49]). The large majority of responding $\mathrm{OB} / \mathrm{GYNs}$ identified as White $(81.3 \%)$, $5.8 \%$ as Hispanic, and $3.9 \%$ as African American. Responding OB/GYNs reported that $45.4 \%$ of their patient population is White, $22.8 \%$ is African American, and $22.6 \%$ is Hispanic. Additional provider and patient demographic information can be found in Table 1. 
Table 1 Demographics of respondents to the full survey

\begin{tabular}{|c|c|}
\hline Characteristics & Percentage or mean \\
\hline \multicolumn{2}{|l|}{ Gender } \\
\hline Male & 50 \\
\hline Female & 50 \\
\hline Age, mean (SD) & $55.8(9.4)$ \\
\hline Years in practice, mean (SD) & $22.8(9.6)$ \\
\hline \multicolumn{2}{|l|}{ Type of practice } \\
\hline OB/GYN partnership /group & 30.4 \\
\hline Solo practice & 21.5 \\
\hline Multi-specialty group & 19.0 \\
\hline University faculty and practice & 17.1 \\
\hline Other & 8.9 \\
\hline HMO (staff model) & 3.2 \\
\hline \multicolumn{2}{|l|}{ Primary specialty } \\
\hline General OB/GYN & 71.3 \\
\hline Gynecology only & 15.3 \\
\hline Other & 8.3 \\
\hline Obstetrics only & 5.1 \\
\hline \multicolumn{2}{|l|}{ Practice location } \\
\hline Urban, non-inner city & 38.9 \\
\hline Suburban & 29.3 \\
\hline Urban, inner city & 18.5 \\
\hline Rural & 12.7 \\
\hline Other & 0.6 \\
\hline \multicolumn{2}{|l|}{$\mathrm{OB} / \mathrm{GYN}$ race } \\
\hline Non-Hispanic, White & 81.3 \\
\hline Asian/Pacific Islander & 7.7 \\
\hline Hispanic & 5.8 \\
\hline African American & 3.9 \\
\hline American Indian/Alaska Native & 0.6 \\
\hline Other & 0.6 \\
\hline \multicolumn{2}{|l|}{ Professional self-identification } \\
\hline Specialist & 49.4 \\
\hline Both PCP and specialist & 48.1 \\
\hline Primary care physician (PCP) & 2.5 \\
\hline \multicolumn{2}{|l|}{ Patient race/ethnicity, mean \% } \\
\hline Non-Hispanic, White & 45.4 \\
\hline African American & 22.8 \\
\hline Hispanic & 22.6 \\
\hline Asian/Pacific Islander & 6.0 \\
\hline Other & 4.7 \\
\hline American Indian/Alaska Native & 1.8 \\
\hline
\end{tabular}

Knowledge

Results supported the hypothesis that African American and Hispanic OB/GYNs would be more knowledgeable of racial/ ethnic disparities in CVD than White OB/GYNs $(F(2,138)=$ 3.30, $p=0.040$ ) (see Table 2). Results also supported the
Table 2 Knowledge of racial/ethnic disparities in CVD by OB/GYN race/ethnicity

\begin{tabular}{lll}
\hline OB/GYN race & Mean knowledge score & SD \\
\hline Hispanic & 0.889 & 0.333 \\
African American & 0.833 & 0.408 \\
White & 0.524 & 0.501 \\
\hline
\end{tabular}

hypothesis that $\mathrm{OB} / \mathrm{GYN}$ practices with increased minority patient populations would predict a greater likelihood that OB/GYNs were knowledgeable about racial/ethnic CVD disparities (OR, 1.02, $95 \%$ CI [1.01, 1.04]; $p=0.010)$. Of all responding $\mathrm{OB} / \mathrm{GYNs}, 57 \%$ were knowledgeable about racial/ethnic disparities in CVD among both African American and Hispanic women, $92.3 \%$ were knowledgeable about CVD disparities among African Americans, and 61.5\% were knowledgeable about CVD disparities among Hispanics. Moreover, the large majority of $\mathrm{OB} / \mathrm{GYNs}$ knew that heart disease is the leading cause of death among women $(97.5 \%)$ and that heart disease mortality differs by gender (79.2\%).

\section{Perceived CVD Risk of OB/GYNs Patient Populations}

$\mathrm{OB} / \mathrm{GYN}$ practices with increased minority patient populations were predictive of providers' perceptions that their patients are at greater risk for CVD compared to White women (OR, 1.03, $95 \%$ CI $[1.01,1.04] ; p=0.002)$. OB/GYNs were asked to rate the prevalence of twelve CVD risk factors among their minority patients relative to White women. Based on their responses to these questions, $\mathrm{OB} / \mathrm{GYN}$ practices with increased minority patient populations predicted greater CVD risk scores $(\beta=0.040, p=0.006)$ (see Table 3). Some providers' perceptions of their patients' CVD risk profile aligned with national prevalence rates of CVD risk factors among minority women relative to White women (i.e., higher rates of obesity, diabetes, metabolic syndrome, racial discrimination, and low SES and lower rates of smoking). It should be noted that although national rates of tobacco use are higher among Whites than African Americans or Hispanics, socioeconomic gradients are stronger predictors of smoking than rates of current only smoking [50]. Research indicates that current smoking, age at initiation, cigarettes per day, years quit, and secondhand smoke all yield strong inverse educational gradients and moderately strong inverse income gradients among Whites and African Americans, with Hispanics having less evident socioeconomic gradients [50]. Racial and ethnic disparities in tobacco-related outcomes may be underestimated due to a focus on current only smoking rates [50]. 
Table 3 Odds ratios of OB/GYNs' perceptions that their minority patient populations are at above average risk for CVD risk factors

\begin{tabular}{lclll}
\hline CVD risk factor & \multicolumn{1}{l}{$B$} & OR & $95 \%$ CI & $p$ value \\
\hline Smoking & -0.008 & 0.992 & $(0.976,1.01)$ & 0.369 \\
Obesity & 0.026 & 1.03 & $(1.01,1.04)$ & $0.005^{*}$ \\
Hypertension & 0.011 & 1.01 & $(0.996,1.03)$ & 0.140 \\
Hyperlipidemia & 0.011 & 1.01 & $(0.996,1.03)$ & 0.156 \\
High blood cholesterol & 0.011 & 1.01 & $(0.996,1.03)$ & 0.156 \\
Diabetes & 0.025 & 1.03 & $(1.01,1.04)$ & $0.002^{*}$ \\
Physical inactivity & 0.010 & 1.01 & $(0.996,1.03)$ & 0.155 \\
Unhealthy diet & 0.013 & 1.01 & $(0.999,1.03)$ & 0.074 \\
Metabolic syndrome & 0.023 & 1.02 & $(1.01,1.04)$ & $0.003^{*}$ \\
Stress & 0.013 & 1.01 & $(0.997,1.03)$ & 0.102 \\
Racial discrimination & 0.024 & 1.03 & $(1.01,1.04)$ & $0.006^{*}$ \\
Low SES & 0.024 & 1.03 & $(1.01,1.04)$ & $0.002^{*}$ \\
\hline
\end{tabular}

${ }^{*} p<0.05$

Attitudes about Racial and Ethnic Disparities in CVD

Association Between Race/Ethnicity and Increased CVD Risks OB/GYNs were asked to indicate their level of agreement with two separate statements that African American race and Hispanic ethnicity are strong CVD risk factors. Although African American race and Hispanic ethnicity are not themselves CVD risk factors, being a minority is associated with several preventable and non-preventable CVD risk factors [17]. This question sought to determine whether OB/GYNs consider patient race/ethnicity as a means of identifying preventable and non-preventable risk factors linked to race/ethnicity.

More OB/GYNs (97.4\%) agreed that African American race is a strong CVD risk factor compared to those $(71.8 \%)$ who agreed that Hispanic ethnicity is a strong CVD risk factor. Responses to these questions differed by provider race/ethnicity. Hispanic (100\%) and African American $(83.3 \%) \mathrm{OB} / \mathrm{GYNs}$ were significantly more likely than White OB/GYNs $(61 \%)$ to agree that Hispanic ethnicity is a strong CVD risk factor $\left(\chi^{2}(2, N=138)=6.55, p=0.038\right)$. Of all responding $\mathrm{OB} / \mathrm{GYNs}, 98.7 \%$ and $71.8 \%$, respectively, believed that African American and Hispanic women in the general U.S. population are at greater risk for CVD relative to White women. When asked specifically about CVD risk among their patients, $96.7 \%$ and $68.1 \%$ of OB/GYNs, respectively, believed that African American and Hispanic women within their practices are at greater risk for CVD relative to White women.

Tailoring CVD Care Differently for Minority Patients OB/ GYNs were given a vignette that asked whether their concern for a patient borderline on a number of objective, physical measures of CVD risk factors (e.g., BMI, hypertension, high cholesterol, etc.) would increase if she were African American, Hispanic, or White. These questions aimed to assess whether OB/GYNs exhibit increased concern for African American and Hispanic women's cardiovascular health, given the consistent evidence that these women are at greater CVD risk at a population wide level $[13,18]$. OB/GYN practices with increased minority patient populations did not predict a greater likelihood that their concern for the patient described in the vignette would increase if she were African American (OR, 1.01, $95 \%$ CI [0.968, 1.05]; $p=0.671)$ or Hispanic (OR, $0.906,95 \%$ CI $[0.991,1.02] ; p=0.365)$. The lack of significant results may be better explained by the lack of variance in responses. Similar to previously discussed findings, a large majority of all responding OB/GYNs $(96.7 \%)$ reported that their concern would increase if the patient were African American, whereas notably fewer OB/GYNs (68.9 \%) indicated that their concern would increase in the patient were Hispanic. Only $25.2 \%$ of OB/GYNs stated that their concern would increase if the patient were White. Answers to the vignette differed significantly based on provider race/ethnicity. Hispanic (100\%) and African American (100\%) OB/GYNs were significantly more likely than White OB/GYNs $(63.6 \%)$ to agree that their concern for the patient would increase if the patient were Hispanic $\left(\chi^{2}(2, N=132)=7.57, p=0.023\right)$.

$\mathrm{OB} / \mathrm{GYNs}$ were also asked whether they agreed that CVD care should be tailored differently for African American and Hispanic women. OB/GYN practices with increased minority patient populations predicted a greater likelihood that $\mathrm{OB} /$ GYNs agreed that CVD care should be tailored differently for African American (OR, 1.02, $95 \%$ CI [1.00, 1.03]; $p=$ 0.018 ) and Hispanic (OR, 1.02 [1.00, 1.04]; $p=0.013$ ) women. Of all responding OB/GYNs, $55.1 \%$ and $43.6 \%$, respectively, agreed that CVD care should be tailored differently for African American and Hispanic women.

\section{Barriers to Providing CVD Care}

OB/GYN practices with increased minority patient populations predicted a greater likelihood that OB/GYNs perceived patients' inability to see a specialist as a patient-related barrier to CVD care (OR, 1.02, $95 \%$ CI [1.01, 1.04]; $p=0.006)$. The most frequently reported provider and patient-related barriers to CVD care were time constraints, patients' nonadherence to treatment recommendations, and lack of sufficient training (see Table 4).

Attitudes Regarding the Professional Role of OB/GYNs and CVD Practice Patterns

Of all responding providers, $71.6 \%$ agreed that CVD health should be a high priority for OB/GYNs. Additionally, 75.2\% agreed that CVD screening is within the professional role of an $\mathrm{OB} / \mathrm{GYN}$, and $68.2 \%$ and $19.1 \%$, respectively, agreed that 
Table 4 Percent age of OB/GYNs who agreed that the following are provider/patient-related barriers to CVD care

\begin{tabular}{ll}
\hline Time constraints & $92.1 \%$ \\
Patient nonadherence to recommendations & $85.6 \%$ \\
Inadequate training & $85.4 \%$ \\
Outside scope of practice & $84.2 \%$ \\
Lack of sufficient knowledge & $82.0 \%$ \\
Lack of reimbursement & $70.7 \%$ \\
Lack of exposure to intermediate/high risk patients & $66.0 \%$ \\
Patients' inability to see a specialist & $58.3 \%$ \\
\hline
\end{tabular}

CVD counseling and management are under their purview. OB/GYNs were asked whether they routinely screen their patients for a number of CVD risk factors. OB/GYN practices with increased minority patient populations (OR, $0.983,95 \%$ CI [0.968, 0.998]; $p=0.025$ ) predicted a decreased likelihood that $\mathrm{OB} / \mathrm{GYNs}$ screen for physical inactivity. OB/GYNs were also asked whether they routinely recommend a number of CVD health-related topics to their patients. OB/GYN practices with increased minority patient populations (OR, 0.963, $95 \%$ CI $[0.935,0.991] ; p=0.012)$ predicted a decreased likelihood that $\mathrm{OB} / \mathrm{GYNs}$ recommend regular exercise.

With regards to CVD practice patterns among all responding $\mathrm{OB} / \mathrm{GYNs}$, only $38.2 \%$ reported that they assess new patients for CVD risk factors most of the time, and slightly over half $(54.5 \%)$ reported that they provide a heart examination to patients most of the time (see Table 5). The large majority of OB/GYNs (92.9\%) reported that they typically refer at-risk patients to a specialist. Of those who refer, $52.3 \%$ reported that they follow-up with the specialist regarding the results, and $71.4 \%$ reported that they discuss the results with the patient. The majority of $\mathrm{OB} / \mathrm{GYNs}$ reported that they routinely screen patients for numerous CVD risk factors and provide routine CVD counseling (see Table 5). However, there appears to be some discrepancy in OB/GYNs' reported screening patterns. Although the large majority of $\mathrm{OB} / \mathrm{GYNs}$ reported that they provide routine screening (see Table 5), when asked how frequently they screen based specifically on patient race/ethnicity, far fewer reported routine screening (see Table 6). Slightly less than half of OB/GYNs ( $48.3 \%$ and $45.9 \%$, respectively) reported that they routinely screen their African American and Hispanic patients for CVD. A greater proportion of $\mathrm{OB} / \mathrm{GYN}$ s reported routinely screening African American and Hispanic women for CVD relative to other races.

\section{Discussion}

It is well established that African American and Hispanic women are at increased risk for CVD and several of its risk factors relative to White women [2]. Research continues to
Table 5 OB/GYN CVD screening and counseling patterns

$\begin{array}{lr}\text { Do you assess new patients for CVD risk factors? (\%) } & \\ \text { Most of the time } & 38.2 \\ \text { Frequently } & 22.3 \\ \text { Sometimes } & 29.3 \\ \text { Rarely/Never } & 10.2 \\ \text { Do you provide a heart examination to your patients? (\%) } \\ \text { Most of the time } & 54.5 \\ \text { Frequently } & 17.3 \\ \text { Sometimes } & 16.0 \\ \text { Rarely/Never } & 12.2\end{array}$

Which of the following CVD risk factors do you routinely screen for among your patients? (\%)

$\begin{array}{ll}\text { Smoking } & 99.4 \\ \text { Obesity } & 98.1 \\ \text { Hypertension } & 96.8 \\ \text { Diabetes } & 65.2 \\ \text { Physical inactivity } & 58.1 \\ \text { High blood cholesterol } & 56.1 \\ \text { Hyperlipidemia } & 54.2 \\ \text { Metabolic syndrome } & 52.9 \\ \text { Unhealthy diet } & 50.3\end{array}$

Which of the following CVD health-related topics do you routinely recommend to your patients? (\%)

$\begin{array}{ll}\text { Smoking cessation } & 98.1 \\ \text { Regular exercise } & 93.6 \\ \text { Weight management/reduction } & 91.7 \\ \text { Blood pressure management } & 84.6 \\ \text { Glycemic control in diabetic patients } & 77.6 \\ \text { Heart-healthy diet } & 66.0 \\ \text { Cholesterol management } & 61.5\end{array}$

underscore the lack of CVD knowledge among both physicians [35] and minority women [37]. Because minority women are more likely to utilize their $\mathrm{OB} / \mathrm{GYN}$ as a PCP, it is crucial that $\mathrm{OB} / \mathrm{GYN}$ be knowledgeable about these disparities and seize opportunities to educate their minority patients regarding their increased risk as well as provide CVD counseling and screening.

Table 6 Frequency with which OB/GYNs reported CVD screening based on patient race/ethnicity

How frequently do you screen the following patients for CVD?

\begin{tabular}{llll}
\hline & Routinely (\%) & $\begin{array}{l}\text { Only in women with } \\
\text { risk factors (\%) }\end{array}$ & $\begin{array}{l}\text { Rarely/ } \\
\text { never (\%) }\end{array}$ \\
\hline African American & 48.3 & 28.9 & 22.8 \\
Hispanic & 45.9 & 28.8 & 25.3 \\
White & 45.3 & 31.8 & 23.0 \\
Asian/Pacific Islander & 41.2 & 25.7 & 33.1 \\
\hline
\end{tabular}


Our findings add to the limited existing literature on $\mathrm{OB} /$ GYN knowledge and practices relevant to racial and ethnic dipartites in CVD among women. The few studies that have assessed OB/GYN knowledge have utilized small and/or geographically limited samples of OB/GYNs [35, 38, 39]. This is the first study to utilize a larger, nationally representative sample of OB/GYNs to assess their knowledge, attitudes, and practice patterns specifically relevant to racial and ethnic disparities in CVD among females.

Our findings indicated that African American and Hispanic $\mathrm{OB} / \mathrm{GYNs}$ and $\mathrm{OB} / \mathrm{GYN}$ with practices with increased minority patient populations were more knowledgeable about racial and ethnic disparities in CVD relative to White $\mathrm{OB} /$ GYNs. Minority physicians are more likely to care for minority patients [42]. It is probable that physicians who have practices with greater minority patient populations are more frequently exposed to at-risk patients relative to those with lower minority patient populations. The large majority of responding OB/GYNs were knowledgeable of racial/ethnic disparities in CVD among African American women, whereas notably fewer were aware of disparities among Hispanic females. These results support previous findings that most $\mathrm{OB} / \mathrm{GYNs}$ are aware that African American women are at greater risk for CVD relative to White women [40]. Our results highlight that racial/ethnic CVD disparities among Hispanic women are less well-known among OB/GYNs. Contrary to previous findings, most OB/GYNs knew that heart disease is the leading cause of death among women and that heart disease mortality rates differ by gender [34, 35].

Although African American race and Hispanic ethnicity are not themselves CVD risk factors, a greater burden of sociodemographic and CVD risk factors, coupled with other patient-related variables, place these groups at increased CVD risk $[13,18]$. We assessed whether $\mathrm{OB} / \mathrm{GYN}$ s consider patient race/ethnicity as a means of identifying preventable and nonpreventable risk factors linked to race/ethnicity. OB/GYN practices with increased minority patient populations were predictive of $\mathrm{OB} / \mathrm{GYNs}$ ' perceptions that their patients are at greater risk for CVD, as well racial discrimination and low SES, relative to White women. The majority of OB/GYNs agreed that their concern would increase for a patient borderline on a number of objective CVD risk factors if she were African American, whereas far fewer agreed that their concern would increase if the patient were Hispanic. These results remain consistent with our previously discussed findings, indicating that OB/GYNs appear to be less concerned about increased CVD risk among Hispanic women. African American and Hispanic $\mathrm{OB} / \mathrm{GYNs}$ were significantly more likely than White $\mathrm{OB} / \mathrm{GYNs}$ to agree that their concern would increase if the patient were African American or Hispanic, indicating differences in providers' attitudes and medical decision-making based on provider race/ethnicity.
OB/GYN practices with increased minority patient populations predicted a greater likelihood that $\mathrm{OB} / \mathrm{GYNs}$ agreed that CVD care should be tailored differently for African American and Hispanic patients. Of all responding $\mathrm{OB} /$ GYNs, slightly over half agreed that CVD care should be tailored differently for African American patients, and less than half agreed that care should be tailored for Hispanics. These opinions are in conflict with medical recommendations that physicians should tailor preventive strategies differently for high-risk groups [51] and use more aggressive interventions for women with multiple CVD risk factors [52].

$\mathrm{OB} / \mathrm{GYN}$ practices with increased minority patient populations predicted a greater likelihood that $\mathrm{OB} / \mathrm{GYN}$ s perceived patients' inability to see a specialist as a patient-related barrier to CVD care. Our results support previous findings indicating that commonly reported provider and patient-related barriers include time constraints, patient nonadherence to medical recommendations, and inadequate training [34, 38, 39]. Endorsed barriers appear to reflect a long-standing problem with regards to socioeconomic disadvantage that many minority groups face as well as persistent mistrust between minority patients and physicians. It is well established that racial/ethnic minority women are at a significant disadvantage regarding access to health care services even when controlling for factors such as SES, insurance coverage, stage or severity of disease, comorbidities, type and availability of health care services, and patient preferences [53]. Research indicates that minority women are less likely to adhere to treatment recommendations compared to White women, and racial discrimination and mistrust in health care providers have been shown to mediate this relationship [54-56].

Only a few differences in CVD practice patterns were found among $\mathrm{OB} / \mathrm{GYN}$ practices with increased minority patient populations. In general, OB/GYNs are screening, counseling, and managing all patients in a similar fashion. Slightly over one third of $\mathrm{OB} / \mathrm{GYNs}$ reported that they assess new patients for CVD risk factors most of the time, and slightly over half of $\mathrm{OB} / \mathrm{GYNs}$ reported that they provide a heart examination to patients most of the time. The majority of $\mathrm{OB} /$ GYNs reported that they routinely screen and provide counseling for numerous CVD risk factors. However, when asked how frequently they screen patients for CVD based specifically on patient race/ethnicity, less than half reported routine screening. The large majority of OB/GYNs reported that they refer at-risk patients to a specialist, and over half reported that they follow-up with the specialist regarding the results.

Our findings indicate that $\mathrm{OB} / \mathrm{GYNs}$ are less knowledgeable about racial/ethnic CVD disparities among Hispanic women and are less likely to agree that CVD care should be tailored differently for these women. These results are concerning given that Hispanic women carry a heavy burden of sociodemographic and CVD risk factors and are more 
likely to utilize their OB/GYN as their PCP $[19,32]$. Notably more research has been conducted investigating African American women's CVD risk. As the Hispanic population in the USA continues to rapidly expand, further research is needed to better understand Hispanic women's CVD risk profile, including various subgroup differences. Our findings suggest that it may be necessary to disseminate educational information to $\mathrm{OB} / \mathrm{GYNs}$ regarding Hispanic women's increased risk for CVD.

Although this study adds significantly to our understanding of current OB/GYNs' knowledge and practice patterns as they relate to racial/ethnic disparities in CVD, it is not without limitations. Data were based on self-report. Thus, it is possible that respondents over- or underestimated actual practice. However, the data that we obtained are important in that they provide a sense of OB/GYNs' knowledge of racial/ethnic CVD disparities and can inform future research and educational training programs. Second, it is possible that responders have greater interest in the topic area than nonresponders and were more willing to complete a survey on CVD, although our nonresponse bias analysis did not suggest differences. Other studies show that nonresponse bias tends to be less problematic in physician surveys than in surveys of the general public [57]. The small percentage of racial and ethnic minority $\mathrm{OB} /$ GYNs in our sample may limit the generalizability of our results. The lack of racial diversity in the physician workforce, including among $\mathrm{OB} / \mathrm{GYNs}$, has long been noted and has remained stable for decades $[27,28,58,59]$. National statistics of the racial and ethnic composition of OB/GYNs [27] and ACOG members $[58,59]$ suggest that our sample is representative. Findings from ACOG's 2003 and 2008 Socioeconomic Survey of a sample of ACOG Fellows indicates that approximately $81 \%$ of responding Fellows identified as White, $5 \%$ as Hispanic, and $4 \%$ as African American, almost identical to our sample (White, $81 \%$; Hispanic, $6 \%$; African American, $4 \%)[58,59]$.

\section{Implications for Practice}

As an increasing number of $\mathrm{OB} / \mathrm{GYNs}$ incorporate primary care into their clinical practices, it is crucial that they are adequately supported and prepared to address important health care issues such as CVD. It is also imperative to recognize that racial/ethnic minority women are more likely to utilize their $\mathrm{OB} / \mathrm{GYN}$ as a PCP. Although OB/GYNs are not responsible for managing their patients' CVD care, they have the opportunity to make a meaningful impact on the cardiovascular health of their minority patients by educating them regarding their increased CVD risk, discussing preventive strategies, and providing basic CVD screening and counseling. Physicians' recommendations heavily influence patients' treatment decisions [60]. Women who receive information about CVD and who know that CVD is their leading cause of death are more likely to take preventive action to decrease their risk [37]. In support of previous findings [38, 39], the majority of respondents indicated that a collaborative care approach to women's health, continuing medical education, and ACOG-supported training in CVD would improve the delivery of CVD care to their patients. Moreover, increased training in multicultural competency offered through medical school, residency, and continuing medical education programs should help OB/GYNs provide culturally competent care to racially diverse patient populations and address frequently reported barriers to CVD care.

Although racial discrimination and access to health care continue to improve for African American and Hispanic women, these groups are still at a major disadvantage when it comes to receiving equal treatment in care. Efforts should focus heavily on narrowing this gap in health care disparities.

Acknowledgement This study was supported by Grant No. UA6MC1901 0 from the Maternal and Child Health Bureau (Title V, Social Security Act, Health Resources and Services Administration, and Department of Health and Human Services (HHS)).

Conflict of Interest Katherine Jones and Drs. Michele Carter and Jay Schulkin declare that they have no conflict of interest.

Informed Consent All procedures followed were in accordance with the ethical standards of the responsible committee on human experimentation (institutional and national) and with the Helsinki Declaration of 1975 , as revised in 2000. Informed consent was obtained from all patients for being included in the study.

\section{References}

1. U.S. Department of Health and Human Services. Healthy People 2010. Washington, DC: U.S. Department of Health and Human Services; 2000.

2. American Heart Association. Heart disease and stroke statistics2014 update: a report from the American Heart Association; 2014. http://www.americanheart.org. Accessed 20 Mar 2014.

3. Mwendwa DT, Sims RC, Madhere S, Thomas J, Keen III LD, Callender $\mathrm{CO}$, et al. The influence of coping with perceived racism and stress on lipid levels in African Americans. J Natl Med Assoc. 2011;103:594-601.

4. Levin S, Sinclair S, Veniegas R, Taylor P. Perceived discrimination in the context of multiple social identities. Psychol Sci. 2002;13:55760.

5. Brondolo E, Rieppi R, Kelly KP, Gerin W. Perceived racism and blood pressure: a review of the literature and conceptual and methodological critique. Ann Behav Med. 2003;25:55-65.

6. Clark R, Anderson NB, Clark VR, Williams DR. Racism as a stressor for African Americans: a biopsychosocial model. Am Psychol. 1999;54:805-16.

7. Brondolo E, Libby DJ, Denton EG, Thompson S, Beatty DL, Schwartz J, et al. Racism and ambulatory blood pressure in a community sample. Psychosom Med. 2008;70:49-56.

8. Harrell JP, Hall S, Taliaferro J. Physiological responses to racism and discrimination: an assessment of the evidence. Am J Public Health. 2003;93:243-8. 
9. Fang CY, Myers HF. The effects of racial stressors and hostility on cardio-vascular reactivity in African American and Caucasian men. Health Psychol. 2001;20:64-70.

10. Wong MD, Shapiro MF, Boscardin WJ, Ettner SL. Contribution of major diseases to disparities in mortality. N Engl J Med. 2002;347: 1585-92.

11. American College of Obstetricians and Gynecologists, Committee on Healthcare for Underserved Women. Challenges for overweight and obese women. Committee Opinion no. 591. Obstet Gynecol. 2014; 123:726-30.

12. Opie LH, Seedat YK. Hypertension in sub-Saharan African populations. Circulation. 2005;112:3562-8.

13. Krousel-Wood M, Thomas S, Muntner P, Morisky D. Medication adherence: a key factor in achieving blood pressure control and good clinical outcomes in hypertensive patients. Curr Opin Cardiol. 2004;19:357-62.

14. Institute of Medicine. Unequal treatment: What healthcare providers need to know about racial and ethnic disparities in health care. Washington, DC: The National Academy of Sciences; 2002. http:// www.iom.edu/ /media/Files/Report\%20Files/2003/UnequalTreatmentConfronting-Racial-and-Ethnic-Disparities-in-Health Care/Disparitieshcproviders8pgFINAL.pdf. Accessed 23 Mar 2012.

15. Smedley BD, Stith AY, Nelson AR, editors. Unequal treatment: confronting racial and ethnic disparities in health care. Washington, DC: The National Academies Press; 2003.

16. Capers IV Q, Sharalaya Z. Racial disparities in cardiovascular care: a review of culprits and potential solutions. J Racial Ethn Health Disparities. 2014. doi:10.1007/s40615-014-0021-7.

17. Cook NL. Minding the competition: racial differences in cardiovascular risk. Circulation. 2012;126:8-10.

18. Berry JD, Dyer A, Cai X, Garside DB, Ning H, Thomas A, et al. Lifetime risks of cardiovascular disease. N Engl J Med. 2012;366: $321-9$.

19. Beohar N, Sansing VV, Davis AM, Srinivas VS, Helmy T, Althouse $\mathrm{AD}$, et al. Race/ethnic disparities in risk factor control and survival in the bypass angioplasty revascularization investigation 2 diabetes (BARI 2D) trial. Am J Cardiol. 2013;112:1298-305.

20. Zhang Y. Cardiovascular disease in American women. Nutr Metab Cardiovasc Dis. 2010;20:386-93.

21. Hu D, Yu D. Epidemiology of cardiovascular disease in Asian women. Nutr Metab Cardiovasc Dis. 2010;20:394-404.

22. Tejero ME. Cardiovascular disease in Latin American women. Nutr Metab Cardiovasc Dis. 2010;20:405-11.

23. Panico S, Mattiello A. Epidemiology of cardiovascular diseases in women in Europe. Nutr Metab Cardiovasc Dis. 2010;20:379-85.

24. Shara NM. Cardiovascular disease in Middle Eastern women. Nutr Metab Cardiovasc Dis. 2010;20:412-8.

25. Laccetti R, Pota A, Stranges S, Falconi C, Memoli B, Bardaro L, et al. Evidence on the prevalence and geographic distribution of major cardiovascular risk factors in Italy. Public Health Nutr. 2012;30:1-11.

26. van Ryn M, Burke J. The effect of patient race and socio-economic status on physician's perceptions of patients. Soc Sci Med. 2000;50: 813-28.

27. Association of American Colleges, diversity in the physician workforce, facts and figures tables. 2010.

28. U.S. Department of Health and Human Services. The rationale for diversity in the health professions: a review of the evidence. 2006. Available at http://bhpr.hrsa.gov/healthworkforce/reports/ diversityreviewevidence.pdf. Retrieved Aug 15, 2014.

29. Hale RW. The obstetrician and gynecologist: primary care physician or specialist? Am J Obstet Gynecol. 1995;172:1181-3.

30. Scholle SH, Kelleher K. Assessing primary care performance in an obstetrics/gynecology clinic. Women Health. 2003;37:15-30.

31. Leddy MA, Lawrence H, Schulkin J. Obstetrician-gynecologists and women's mental health: Findings of the Collaborative Ambulatory Research Network 2005-2009. Obstet Gynecol Surv. 2011;66:1-9.
32. Henderson JT, Weisman CS, Grason H. Are two doctors better than one? Women's physician use and appropriate care. Womens Health Issues. 2002;12:138-49.

33. American College of Obstetricians and Gynecologists. Guidelines for women's health care: a resource manual. Obstetrics \& Gynecology (3rd ed., pp. 1-313). Washington, DC: American College of Obstetricians and Gynecologists; 2007.

34. Barnhart J, Lewis V, Houghton JL, Charney P. Physician knowledge levels and barriers to coronary risk prevention in women: survey results from the Women and Heart Disease Physician Education Initiative. Womens Health Issues. 2007;17:93-100.

35. Mosca L, Linfante AH, Benjamin EJ, Berra K, Hayes SN, Walsh BW, et al. National study of physician awareness and adherence to cardiovascular disease prevention guidelines. JAMA. 2005;111:499-510.

36. Mosca L, Ferris A, Fabunmi R, Robertson RM. Tracking women's awareness of heart disease: an American Heart Association National study. JAMA. 2004;109:573-9.

37. Mosca L, Mochari H, Christian A, Berra K, Taubert K, Mills T, et al. National study of women's awareness, preventive action, and barriers to cardiovascular health. JAMA. 2006;113:525-34.

38. Ehrenthal DB, Núñnes AE, O’Neill E, Robertson-James C, Addo SF, Stewart A. The role of the obstetrician/gynecologist in the prevention of cardiovascular disease in women. Womens Health Issues. 2011;5: 338-44.

39. Morgan MA, Lawrence H, Schulkin J. Obstetrician-gynecologists' approach to well-woman care. Obstet Gynecol. 2010;116:715-22.

40. Ehrenthal DB, Haynes SG, Martin KE, Hitch JA, Addo SF, O'Neill E, et al. Evaluation of the Heart Truth Professional Education Campaign on provider knowledge of women and heart disease. Womens Health Issues. 2010;23:e87-93.

41. Giardiana EV, Sciacca RR, Flink LE, Bier ML, Paul TK, Moise N. Cardiovascular disease knowledge and weight perception among Hispanic and non-Hispanic White women. J Womens Health. 2013;22:1009-15.

42. Komaromy M, Grumbach K, Drake M, Vranizan K, Lurie N, Keane $\mathrm{N}$, et al. The role of Black and Hispanic physicians in providing health care for underserved populations. N Engl J Med. 1996;334: 1305-10.

43. Kressin NR, Wang F, Long J, Bokhour BG, Omer MB, Rothendler J, et al. Hypertensive patients' race, health beliefs, process of care, and medication adherence. J Gen Intern Med. 2007;22:768-74.

44. Mebane EW, Oman RF, Kroonen LT, Goldsteain MK. The influence of physician race, age, and gender on physician attitudes toward advance care directives and preferences for end-of-life decision-making. J Am Geriatr Soc. 1999;47:579-91.

45. Hill LD, Erickson K, Holzman G, Power ML, Schulkin J. Practice trends in outpatient obstetrics and gynecology: Findings of the Collaborative Ambulatory Research Network 1995-2000. Obstet Gynecol Surv. 2001;56:505-16.

46. Hall JA, Irish JT, Roter DL, Ehrlich CM, Miller LH. Gender in medical encounters: an analysis of physician and patient communication in a primary care setting. Health Psychol. 1994;13:384-92.

47. Roter DL, Hall JA. Why physician gender matters in shaping the physician patient relationship. J Womens Health. 1998;7:1093-7.

48. Raglan GB, Margolis B, Paulus R, Schulkin J. Electronic health record adoption among obstetrician/gynecologists in the United States: physician practices and satisfaction.J Healthc Qual. 2014:1-8

49. Vink J, Anderson B, Fuchs K, Schulkin J, D'Alton ME. Opinions and practice patterns of obstetricians-gynecologists in the United States regarding amniocentesis in twins. Prenat Diagn. 2013:899-903

50. Margerison-Zilko C, Cubbin C. Socioeconomic disparities in tobacco-related health outcomes across racial/ethnic groups in the United States: national health interview survey 2010. Nicotine Tob Res. 2013;15:1161-5. 
51. Stranges S, Guallar E. Cardiovascular disease prevention in women: a rapidly evolving scenario. Nutr Metab Cardiovasc Dis. 2012;22:1013-8.

52. Perrone G, Brunelli R. Prevention and treatment of cardiovascular disease in women: the obstetric-gynecologist's point of view. Ther Apher Dial. 2013;17:162-8.

53. Mayberry RM, Mill F, Ofili E. Racial and ethnic differences in access to medical care. Med Care Res Rev. 2000;57:108-45.

54. Bosworth HB, Powers B, Grubber JM, Thorpe CT, Olsen MK, Orr $\mathrm{M}$, et al. Racial Differences in blood pressure control: potential explanatory factors. J Gen Intern Med. 2008;23:692-8.

55. Cuffee YL, Hargraves JL, Rosal M, Briesacher BA, Schoenthaler A, Person $\mathrm{S}$, et al. Reported racial discrimination, trust in physicians, and medication adherence among inner-city African Americans with hypertension. Am J Public Health. 2013;103:e55-62.

56. O'Malley AS, Sheppard VB, Schwartz M, Mandelblatt J. The role of trust in use of preventive services among low-income AfricanAmerican women. Prev Med. 2004;38:777-85.
57. Kellerman SE, Herold J. Physician response to surveys. A review of the literature. Am J Prev Med. 2001;20:61-7.

58. American College of Obstetricians and Gynecologists. Profile of obgyn practice. Washington, DC: ACOG; 2004. Available at: http:// www.acog.org/ /media/Departments/Practice/ProfileofObgynPractice1991-2003.pdf?dmc=1\&ts=20140814T0929418526. Retrieved August 14, 2014.

59. American College of Obstetricians and Gynecologists. 2008 socioeconomic survey of ACOG Fellows (unpublished data not included in online report). Washington, DC: ACOG; 2009. Available at: http://www.acog.org/About-ACOG/ACOGDepartments/Practice-Management-and-Managed-Care/2008Socioeconomic-Survey-of-ACOG-Fellows. Retrieved August 14, 2014.

60. Gurmankin AD, Baron J, Hershey JC, Ubel PA. The role of physicians' recommendations in medical treatment decisions. Med Decis Mak. 2002;22:26-71. 